\title{
Aspectos Metodológicos de la Danza en el Desarrollo de Destrezas Normadas en el Currículo Ecuatoriano
}

\section{Methodological Aspects of Dance in the Development of Standardized Skills in the Ecuadorian Curriculum}

\author{
Santiago Benigno Moscoso-Jácome \\ santiago.moscoso.83@est.ucacue.edu.ec \\ Universidad Católica de Cuenca, Azogues \\ Ecuador \\ https://orcid.org/0000-0002-3907-2349 \\ Juan Carlos Bayas-Machado \\ juan.bayas@ucacue.edu.ec \\ Universidad Católica de Cuenca, Azogues \\ Ecuador \\ https://orcid.org/0000-0002-5599-9240 \\ Ximena Alexandra Astudillo-Astudillo \\ ximena.astudilloa@ucacue.edu.ec \\ Universidad Católica de Cuenca, Azogues \\ Ecuador \\ https://orcid.org/0000-0002-9858-4758
}

Recepción: 30 de agosto 2021 Revisado: 20 de septiembre 2021 Aprobación: 15 de noviembre 2021 Publicación: 01 de diciembre 2021 


\title{
RESUMEN
}

El presente artículo científico tiene como objetivo desarrollar una guía metodológica para la enseñanza de la danza por medio de las destrezas normadas en el currículo ecuatoriano. Se utilizó un diseño no experimental puesto que las variables de estudio no se manipularon, de tipo descriptivo. A manera de conclusión se puede considerar que la práctica de la danza tiene varios beneficios, los cuales han sido recalcados a lo largo de este trabajo, lo primordial es proponer los fundamentos que harán que la práctica de la danza sea importante. En este estudio se destacan aspectos que se deben abordar para conseguir cambios en los estudiantes. Sin duda alguna es importante la capacitación de los docentes en el campo artístico de la danza, ya que así se cumplirá con los objetivos que se persiguen a través de su práctica.

Descriptores: Danza tradicional; folklore; aprendizaje activo. (Palabras tomadas del Tesauro UNESCO).

\begin{abstract}
The objective of this scientific article is to develop a methodological guide for the teaching of dance through the skills regulated in the Ecuadorian curriculum. A non-experimental design was used since the study variables were not manipulated, of a descriptive type. In conclusion, it can be considered that the practice of dance has several benefits, which have been emphasized throughout this work, the main thing is to propose the fundamentals that will make the practice of dance important. This study highlights aspects that must be addressed to achieve changes in students. Undoubtedly, the training of teachers in the artistic field of dance is important, since in this way the objectives pursued through their practice will be met.
\end{abstract}

Descriptors: Traditional dance; folklore; activity learning. (Words taken from the UNESCO Thesaurus). 


\section{INTRODUCCIÓN}

La Educación Física atribuye varios desafíos a la sociedad educativa, debido a esto, los docentes de modo constante indagan opciones que les permitan dar respuestas afirmativas a estas exigencias, la presente investigación aborda de aspectos metodológicos de la Danza en el desarrollo de destrezas normadas en el currículo ecuatoriano emitido por el Ministerio de Educación, mismo que se sub divide en seis bloques curriculares, siendo uno de ellos el bloque movimientos expresivos comunicativos (Mineduc, 2016), para esto se ha considerado los resultados de investigaciones favorables en varias bases de datos científicos del tema tratado.

En este contexto, podemos destacar que la danza en los últimos años ha sido considerada una estrategia metodológica que favorece el desarrollo de habilidades y destrezas en las personas, de la misma manera beneficia el desarrollo del aprendizaje, es por ello que para poder utilizar como un instrumento de enseñanza - aprendizaje en la educación es importante que los docentes organicen, planifiquen, midan y evalúen el proceso de aprendizaje, por otra parte, se puede decir que la danza es la base de la didáctica para conseguir un modelo desarrollador e integrador visto desde un enfoque pedagógico, que por medio de sus elementos dirige su formación de la comunidad educativa y con ello se plantea la necesidad de expresar nuestros sentimientos desde un enfoque creativo, desarrollando todas las capacidades humanas que dan importancia al servicio educativo (Lozano, 2012)

De la misma manera Ávila y Veytia (2019), mencionan que el enfoque socioformativo, sugiere una re conceptualización del campo académico y profesional concibiendo la institución educativa como un espacio en el cual distintas personas trabajan en al mismo tiempo para solucionar problemas en el ámbito educativo y así desarrollar un sólido proyecto de vida que promueva la cooperación como eje metodológico para que las instituciones educativas logren formar a todos los estudiantes y consigan alcanzar las 
destrezas requeridas, independientemente de la condición física, cognitiva o sociocultural de cada uno.

El problema de esta investigación se relaciona con la aplicación del contenido del bloque movimientos expresivos - comunicativos y los aspectos metodológicos que inciden en el desarrollo de destrezas las cuales están normadas en el currículo ecuatoriano y ejecutadas por los docentes responsables de la asignatura, sean estos especialistas o en la mayoría de los casos docentes encargados de impartir las horas asignadas a Educación Física, siendo estos últimos, la principal razón para no poder desarrollar el contenido del currículo y con ello, la adquisición de destrezas requeridas las mismas que perjudican en el aprendizaje del estudiante y con estas deficiencias pasan al siguiente subnivel educativo con grandes desventajas en el aprendizaje.

En este aspecto, es indispensable mencionar que en el país se le da poca importancia a la danza como una metodología de aprendizaje, lo cual ha generado dificultades en el desarrollo de habilidades motoras y cognitivas del estudiante, a pesar que en el transcurso de estos últimos años se le ha dado más relevancia a la danza dentro del currículo y como muestra de ello se elaboraron guías metodológicas que ayudan al docente en el desarrollo de la clase, destacando el bachillerato artístico especializado en danza (2014), que se creó con la expectativa de aplicar las técnicas básicas de la danza ecuatoriana y con la capacitación satisfacer necesidades artístico - culturales y así aportar en la consolidación de la nacionalidad e interculturalidad del país.

Por consiguiente, la danza se la considera como un medio de expresión, más no como un método de enseñanza y aprendizaje, por consiguiente, el objetivo general de este estudio es desarrollar una guía metodológica para la enseñanza de la danza por medio de las destrezas normadas en el currículo ecuatoriano, la cual sirva como un manual para que los docentes trabajen en las clases y así favorecer el aprendizaje y desarrollo psicomotor y cognitivo de los estudiantes conjuntamente con fines investigativos se empleará diferentes técnicas y métodos de la investigación científica, entre las que se 
evidencia la aplicación de una encuesta, misma que fue validada por docentes especialistas de la asignatura de Educación Física, lo que ayudó a conocer el nivel de conocimiento de los docentes investigados.

\section{Referencial teórico}

\section{Danza}

La danza es la puesta en escena de imitación o sátira a los conquistadores, que al pasar los años han ido cambiando la forma de movimientos por las nuevas costumbres, tradicionales y folclóricas que se están rescatando nuevamente, a los movimientos vivos. Ante ello, (Escobar, 2005), menciona que se puede acrecentar las posibilidades del movimiento reconociendo el cuerpo y con ello buscar la relajación, equilibrio, lateralidad, con el ejercicio, es decir que los movimientos en diferentes planos corporales del estudiante deben ser reconocidos tanto en la ubicación y desenvolvimiento, como en el tiempo de realización rítmica y corporal.

El folclor y la danza, son parte de la identidad de un pueblo que con dicha expresión cultural plasma gustos, costumbres y creencias del pueblo, por su parte Montufar (2011) comenta que "es muy importante considerar a la danza folclórica como parte del currículo de Educación Física y bachillerato rescatando identidad y cultura desde muy tempranas edades teniendo en cuenta la inclusión educativa" (p. 10).

En el proceso educativo el maestro debe motivar la identidad cultural a través de danzas autóctonas de los pueblos ecuatorianos. Según De la Torre y Coba (2013) sostienen que el ritmo del Sanjuanito es el primer pentafónico y el segundo género de danza autóctona ecuatoriana ya que, al ser un baile de pareja, se refleja en el mismo, un trabajo de carácter social no se puede dejar de mencionar su compás de 2/4 en movimiento Allegro moderato y que tiene estribillo. 


\section{Enfoque pedagógico de la danza}

La danza es considera como aquella acción del cuerpo humano que con su movimiento provoca una actividad que vive en incesante correlación con el medio y en correspondencia continua con los procesos de aprendizaje, crecimiento, y maduración por los en las diferentes etapas de la vida (Ferreira, 2017).

Según Monroy (2003), menciona que:

Pedagogía de la danza sugiere indagar deliberadamente sobre la naturaleza de la expresión humana, pues la improvisación -desde la perspectiva de la incompetencia y la no planeación- no es admisible en cuanto a la formación artística de las niñas y los niños, ni en cuanto a los procesos de creación de productos escénicos. Por lo tanto, para el maestro, se exige un alto grado de conocimiento y creatividad. La danza es a lo lúdico como el amor a la vida. (p.159)

Del mismo modo, se considera a la danza como un proceso creativo que se concatena emocionalmente con el primer impulso de la necesidad de bailar, ante esta referencia los docentes de Educación Física deben planificar considerando el desarrollo de la kinestésica que se encuentra en la motricidad gruesa y fina para ir formando lateralidad, y coordinación del cuerpo. Los tres ámbitos de la conducta humana.

Por consiguiente, se establece a la Danza como intermedio en el proceso formativo desarrollador del estudiante, no debiendo centrarse únicamente en la enseñanza de nuevas técnicas o de pasos preestablecidos a consecuencia de esto, la danza pretende crear experiencias corporales placenteras, en la que se adecuen ambientes con el fin de que el estudiante pueda aprender de una manera significativa. Del mismo modo, la metodología de enseñanza que promulgó Musska Mosston en los años 60, son muy ajustables a una nueva propuesta educativa con relación a la danza, tomando en cuenta las particularidades de la danza al ser un lenguaje mundial único y artístico, visto desde esta perspectiva los diferentes estilos y métodos de la Danza son analizados desde un enfoque educativo, por lo tanto, según los objetivos propuestos y los contenidos de la danza, estos serán característicos para la enseñanza de los estudiantes (Ferreira, 2009) 


\section{La danza en el currículo ecuatoriano}

En este sentido y desde una retrospectiva del currículo en el Ecuador, se crean diferentes reformas curriculares pudiendo señalar las siguientes en orden cronológico. En 1978 se funda la Dirección Nacional de Deportes, Educación Física y Recreación, reconocidas por sus siglas como (DINADER), seguido a esto se crean los programas de estudio en niveles primarios reconocidos por DINADER (1981), en los cuales se observa poco interés por la aplicación de la danza en el contenido del currículo, después de algunos años interviene Mineduc junto al Consejo Nacional de Deportes, resaltando el convenio ecuatoriano alemán en el año 1991, donde la danza ya es parte del proceso enseñanza aprendizaje denotando las actividades en sus guías didácticas anexadas al convenio. Luego a esto tenemos la reforma curricular para la educación básica y bachillerato en el año 1997; la cual se quedará hasta la llegada del currículo 2012 y por último se mantiene vigente, el currículo actual (Mineduc, 2016).

Teniendo en cuenta que a partir del currículo 2012, se considera a la danza como parte de las destrezas a desarrollar en el bloque curricular denominado Movimiento formativo, artístico y expresivo, el que plantea diferentes posibilidades de movimiento como son la danza, el baile, y las rondas que son una muestra de la expresión corporal los cuales son un elemento fundamental de la formación integral en la Educación Física (Mineduc, 2012) Del mismo modo el currículo de Educación Física vigente 2016, con el bloque curricular denominado Prácticas corporales expresivo-comunicativas, considera a la danza capaz de asociarse con el arte de tal forma la danza es considerada como historias narradas por medio del baile, con la finalidad de expresar las posibilidades, talentos y virtudes que se reflejan en la capacidad de desarrollar destrezas tanto deseables como imprescindibles. 


\section{MÉTODO}

La presente Investigación tiene un enfoque mixto, tipo descriptivo no experimental, la información fue recolectada una sola ocasión, es cuantitativa por que se utiliza procesos matemáticos valores estadísticos, utilizamos los datos que arrojan las encuestas aplicadas en la investigación (Erazo, 2021). Es cualitativa porque se va a estudiar los puntos de vista metodológicos de la Danza en el progreso de destrezas normadas en el currículo ecuatoriano, se utilizará también el método bibliográfico, documental debido a que va a permitir examinar, verificar, desarrollar, ahondar y comparar otros puntos de vista de autores, conjeturas, razonamientos, teorías y temas relativos a la danza, así mismo se manejará el método deductivo que consiente el análisis de información, partirá de conceptos generales para llegar a una conclusión concreta y el método analítico que consiente efectuar un estudio en partes de acuerdo a sus tipos y cualidades (Erazo y Narváez, 2020).

La población fue constituida por 300 docentes pertenecientes al distrito 06D01 ChamboRiobamba, la muestra fue de 200 docentes encuestados, las mismas que fueron respondidas por 150 profesores especialistas en el área de Educación Física y 50 por profesores de diferentes áreas pero que están impartiendo Educación Física, se empleó un instrumento tipo cuestionario de 13 ítems, la propia que fue respondida de forma digital a través de la herramienta Google Forms, para la validación del instrumento se realizó por expertos. El análisis estadístico se realizó a través del paquete informático SPSS versión 19.

\section{RESULTADOS}


A continuación se presentan los resultados luego del proceso de recolección de datos:

¿Cree usted que es preciso incrementar en las clases de Educación Física, la práctica de la danza?

\section{Tabla 1}

Práctica de la danza.

\begin{tabular}{ccc}
\hline Opciones & $\begin{array}{c}\text { Frecuencia } \\
\text { absoluta }\end{array}$ & $\begin{array}{c}\text { Frecuencia } \\
\text { relativa }\end{array}$ \\
\hline $\mathrm{Si}$ & 187 & $93 \%$ \\
No & 3 & $2 \%$ \\
Tal vez & 10 & $5 \%$ \\
Total & 200 & $100 \%$ \\
\hline
\end{tabular}

Fuente: Encuestados

Como muestra la tabla 1 según los docentes encuestados los 187 corresponde a un $93 \%$ del total creen que sí se debe incrementar la danza, mientras que dan respuesta de No, que corresponde a 3 docentes que concierne a un $2 \%$ cree que no se debe incrementar la danza y un talvez que corresponde al $5 \%$ que son 10 docentes del total de encuestados nos dicen que puede ser importante.

Se observa que el fortalecimiento de la Danza es importante para mejorar la Educación Física mediante la música ya que con esta podemos rescatar culturas y las clases sean más motivadoras para los estudiantes. 
¿Cree usted que debe considerarse en el aprendizaje una planificación de Danza en las instituciones?

\section{Tabla 2.}

Planificación de Danza en las instituciones.

\begin{tabular}{lcl}
\hline Opciones & $\begin{array}{l}\text { Frecuencia } \\
\text { Absoluta }\end{array}$ & $\begin{array}{l}\text { Frecuencia } \\
\text { relativa }\end{array}$ \\
\hline Si & 179 & $89 \%$ \\
No & 5 & $3 \%$ \\
Tal vez & 16 & $8 \%$ \\
\hline Total & 200 & $100 \%$
\end{tabular}

Fuente: Encuestados

En la tabla 2, de los 200 encuestados los 179 docentes que correspondiente al 89\% nos da a conocer que, si es importante la planificación de la Danza para potencializar su aprendizaje en las instituciones educativas, por otra parte 5 educadores que equivale al $3 \%$ dice que no es necesario una planificación para la ejecución de la Danza y a su vez 16 pedagogos nos comparte que tal vez es necesario considerar la planificación para impartir la Danza dentro de los planteles educativos. 
¿Considera usted que la aplicación de metodologías de la Danza mejora las habilidades y destrezas de los estudiantes?

Tabla 2

Metodologías de la Danza

\begin{tabular}{lll}
\hline Opciones & $\begin{array}{l}\text { Frecuencia } \\
\text { absoluta }\end{array}$ & $\begin{array}{l}\text { Frecuencia } \\
\text { relativa }\end{array}$ \\
\hline Si & 184 & $91 \%$ \\
No & 3 & $2 \%$ \\
Tal vez & 13 & $7 \%$ \\
\hline Total & 200 & $100 \%$
\end{tabular}

Fuente: Encuestados

Como podemos apreciar en la tabla 3, se ha encuestado a los 200 docentes obteniendo la aceptación del 184 de ellos que equivales al $91 \%$ que nos exponen que, si es importante la metodología para a Danza, por otra parte 3 docentes que equivale al $2 \%$ nos da como resultado que No es importante la aplicación de metodologías y $7 \%$ que son 13 educadores nos indican que tal vez sería bueno impartir la danza por medio de diferentes metodologías.

Se conoce que la mayoría de encuestados menciona la aceptación de la aplicación de metodologías de la Danza siendo beneficiados los estudiantes ya que pueden alcanzar niveles superiores en las habilidades y destrezas. 
¿Cree usted que es de suma importancia la elaboración de una guía metodológica en Danza Folclórica que facilite al docente a impartir las clases de Educación Física?

Tabla 4.

Guía metodológica en Danza Folclórica.

\begin{tabular}{lll}
\hline Opciones & $\begin{array}{l}\text { Frecuencia } \\
\text { absoluta }\end{array}$ & $\begin{array}{l}\text { Frecuencia } \\
\text { relativa }\end{array}$ \\
\hline Si & 168 & $83 \%$ \\
No & 7 & $4 \%$ \\
Tal vez & 25 & $13 \%$ \\
\hline Total & 200 & $100 \%$
\end{tabular}

Fuente: Encuestados

Se observan los resultados de la tabla 4, de los 200 encuestados 168 que equivale al $83 \%$ nos indica que si es importante la elaboración de una guía para la danza mientras que 7 docentes que son el 4\% expresa que no necesitan una guía metodológica para la Danza, 25 educadores que es el 13\% nos muestra que tal vez sería necesario la implementación de la guía para la enseñanza aprendizaje.

Se interpreta que los encuestados la mayoría da conocer que si es importante la elaboración y ejecución de una guía metodológica en Danza folclórica para las clases de Educación Física con esto los estudiantes se motiven para aprender y ejecutar dentro y fuera de las unidades educativas. 


\section{DISCUSIÓN}

El estudio realizado a docentes de Educación Física ayudó a verificar que la danza es fundamental en el desarrollo de diferentes habilidades motrices básicas, el baile, la música, el movimiento son partes primordiales para el desarrollo de los alumnos, mediante una guía metodológica de danza planteada en esta investigación nos ayuda a desarrollar ejercicios para mejorar la expresión corporal.

La danza es la expresión para manifestar diferentes sentimientos, de la misma forma desarrolla destrezas, habilidades cognitivas y desarrollo motriz, en edades tempranas, combinamos movimientos con música mejorando la expresión corporal.

Cada Docente sostiene que la danza es un factor importante que desarrolla las habilidades motrices básicas es de mucha importancia la guía planteada en esta investigación de los principales ritmos del Ecuador, con la música y el ritmo los niños mejoran su coordinación, mejoran en otras asignaturas al desarrollar la motricidad fina y gruesa mediante los sonidos y ejercicios, por lo tanto, la danza ayuda a los niños a adquirir destrezas, desarrollándose físicamente Patajalo, socialmente y cognitivamente (Cadenillas, 2016). Con las consecuencias anteriormente manifestadas, pretende el autor exponer pasos de danza que ayuden a mejorar sus habilidades motrices mediante la música y pasos básicos posibles para su ejecución.

\section{PROPUESTA}

\section{Diseño y Ejecución de una Guía Metodológica}

La educación en general en nuestro medio, requiere de cambios constructivos y valorativos, siendo la danza uno de los elementos que mejorará notablemente las habilidades motrices básicas y nuestra identidad cultural, que nos permitirá expresar y valorar nuestras costumbres y tradiciones.

La danza ecuatoriana como "identidad nacional", debe ser considerada como una asignatura de estudio para los docentes que dictan clases de Educación Física las cuales 
nos van a permitir desarrollar de mejor manera las capacidades motrices de los estudiantes.

El diseño y ejecución de una guía metodológica, facilita la ejecución de movimientos y ejercicios en los cuales nos explicarán de mejor manera, para poder llevar una clase de Educación Física dentro del tercer bloque del currículo de Educación Física del año 2016, las prácticas corporales expresivas-comunicativas, en esta unidad se encuentra la danza que a través de ella se puede desarrollar diferentes destrezas en los educandos y de esta manera contribuir en conocimientos a los docentes para que puedan llevar de una mejor manera las clases, dentro de esta guía están clases planificadas para que el aprendizaje sea llevado de una mejor manera, también se podrá promover la identidad cultural.

Conocedor que los docentes de Educación Física de Unidades Educativas evitan trabajar el tercer bloque del currículo del ministerio de Educación del 2016 y especialmente la danza por conocer poco la cultura ecuatoriana o por otros motivos diferentes se considera que de suma importancia crear esta guía metodológica para los docentes, esto ayudará a iniciar la práctica de bailes ecuatoriano en las clases de Educación Física. Por el valor y potencial didáctico que representará para muchos aprendizajes que incide positivamente en el desarrollo artístico - cultural, físico e intelectual, por este fundamento el docente de Educación Física debe estar capacitado para promover este tipo de actividad física.

Crear una guía metodológica para los docentes de Educación Física, para mejorar sus conocimientos de la danza folclórica y puedan ser aplicados en las clases con los alumnos para un mejor desarrollo de las diferentes habilidades ya sean artístico, cultural, físico e intelectual.

Motivar a los estudiantes a la práctica de la danza ecuatorianas para mejorar las habilidades y destrezas dancísticas.

Capacitar a los docentes, sobre estrategias de la práctica de la danza folclórica 
Revista Arbitrada Interdisciplinaria KOINONIA

Año VI. Vol VI. N4. Edición Especial: Educación III. 2021

Hecho el depósito de Ley: FA2016000010 ISSN: 2542-3088

FUNDACIÓN KOINONIA (F.K). Santa Ana de Coro. Venezuela.

Santiago Benigno Moscoso-Jácome; Juan Carlos Bayas-Machado; Ximena Alexandra Astudillo-Astudillo

\section{ecuatoriana en la Educación Física.}




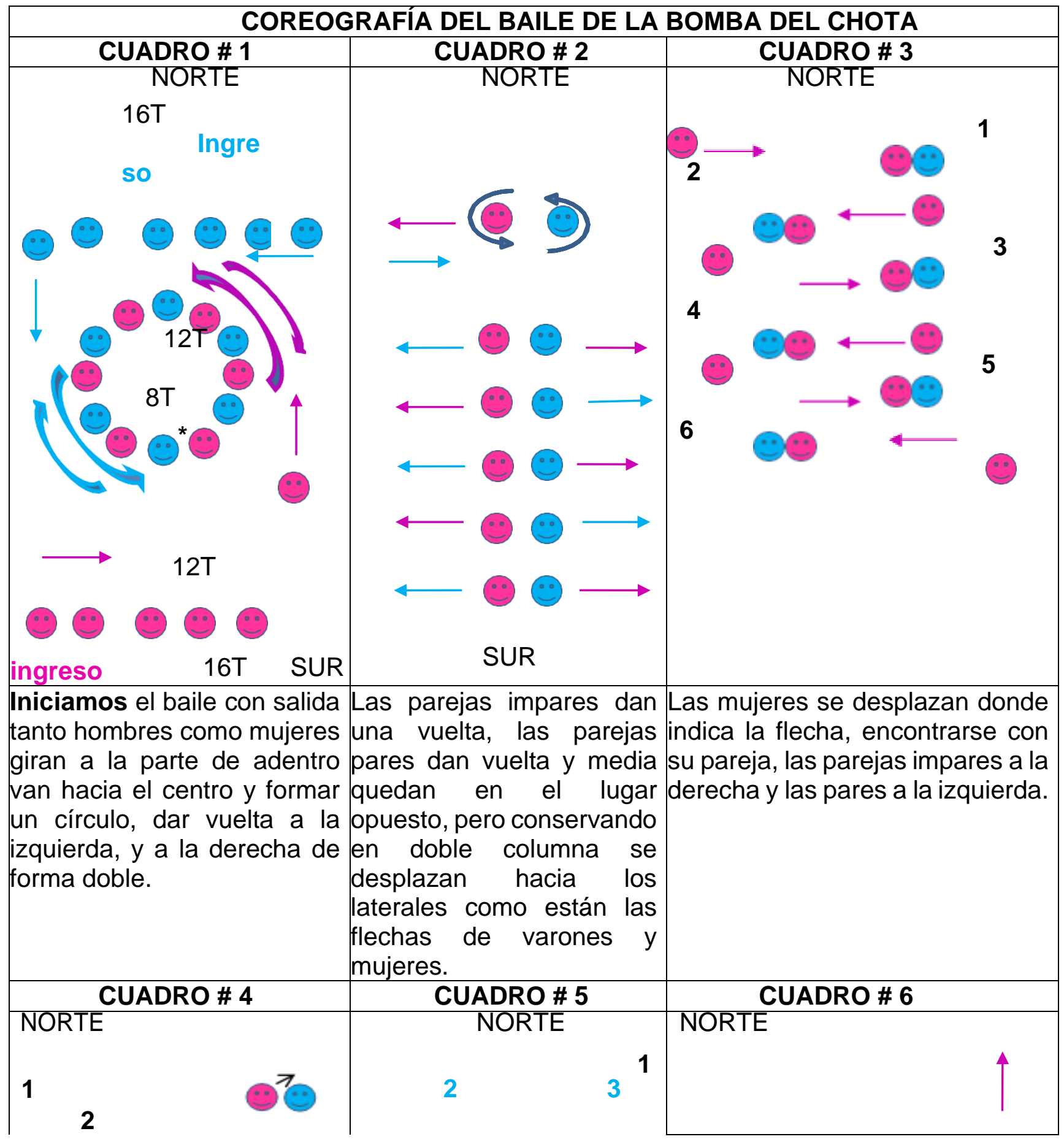


Revista Arbitrada Interdisciplinaria KOINONIA

Año VI. Vol VI. N4. Edición Especial: Educación III. 2021

Hecho el depósito de Ley: FA2016000010

ISSN: 2542-3088

FUNDACIÓN KOINONIA (F.K). Santa Ana de Coro. Venezuela.

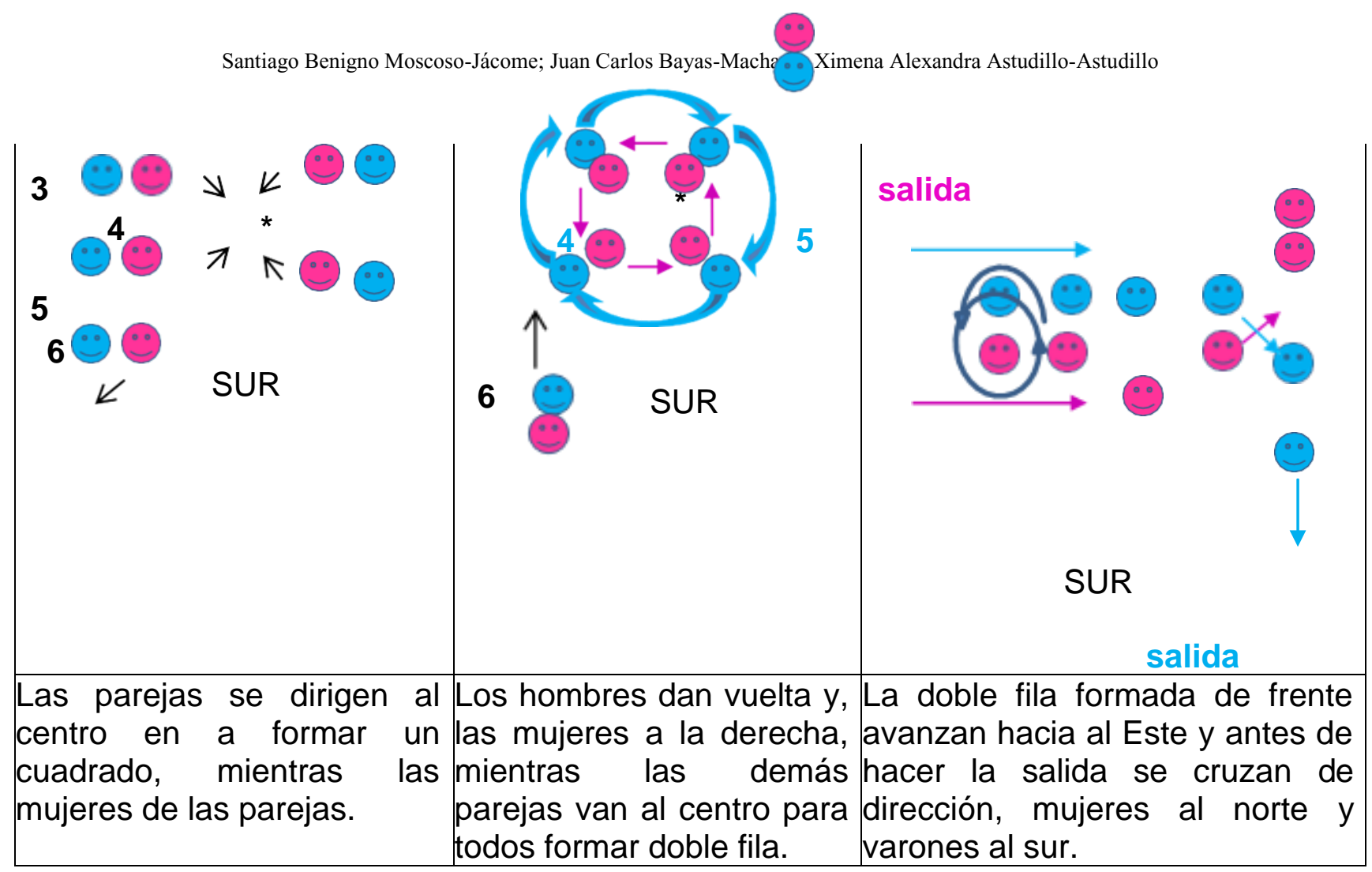

Gráfico 1. Coreografía la Bomba del Chota

Fuente: Los autores 


\section{METODOLOGÍA DE LA COREOGRAFÍA DEL SAN JUANITO}

\begin{tabular}{|l|l|c|c|}
\hline CUADRO \# 1 & CUADRO \# 3 \\
\hline Ingreso
\end{tabular}




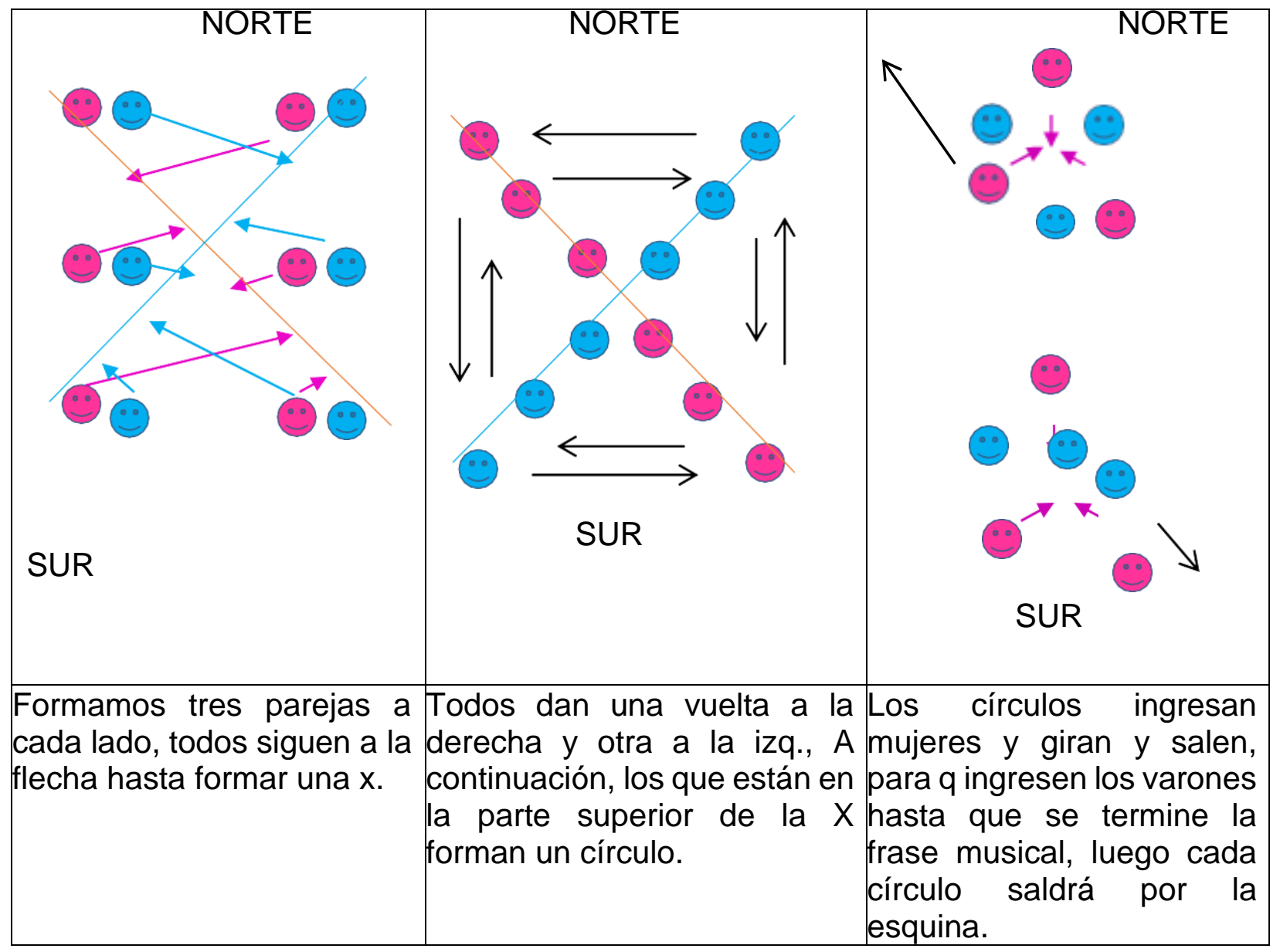

Gráfica 2: Coreografía del san Juanito Fuente: Los autores 
METODOLOGÍA DE LA COREGRAFÍA DEL PASACALLE

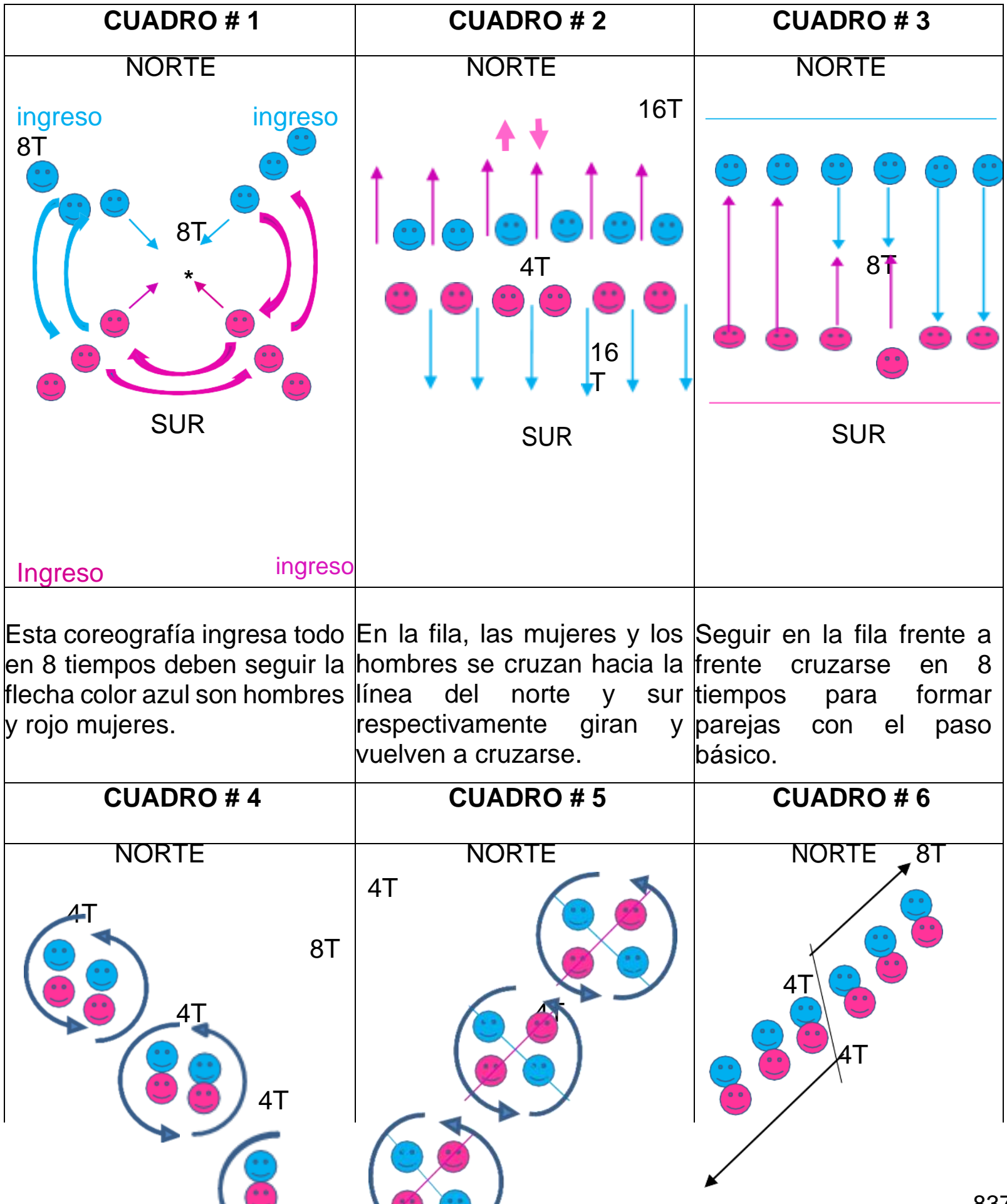




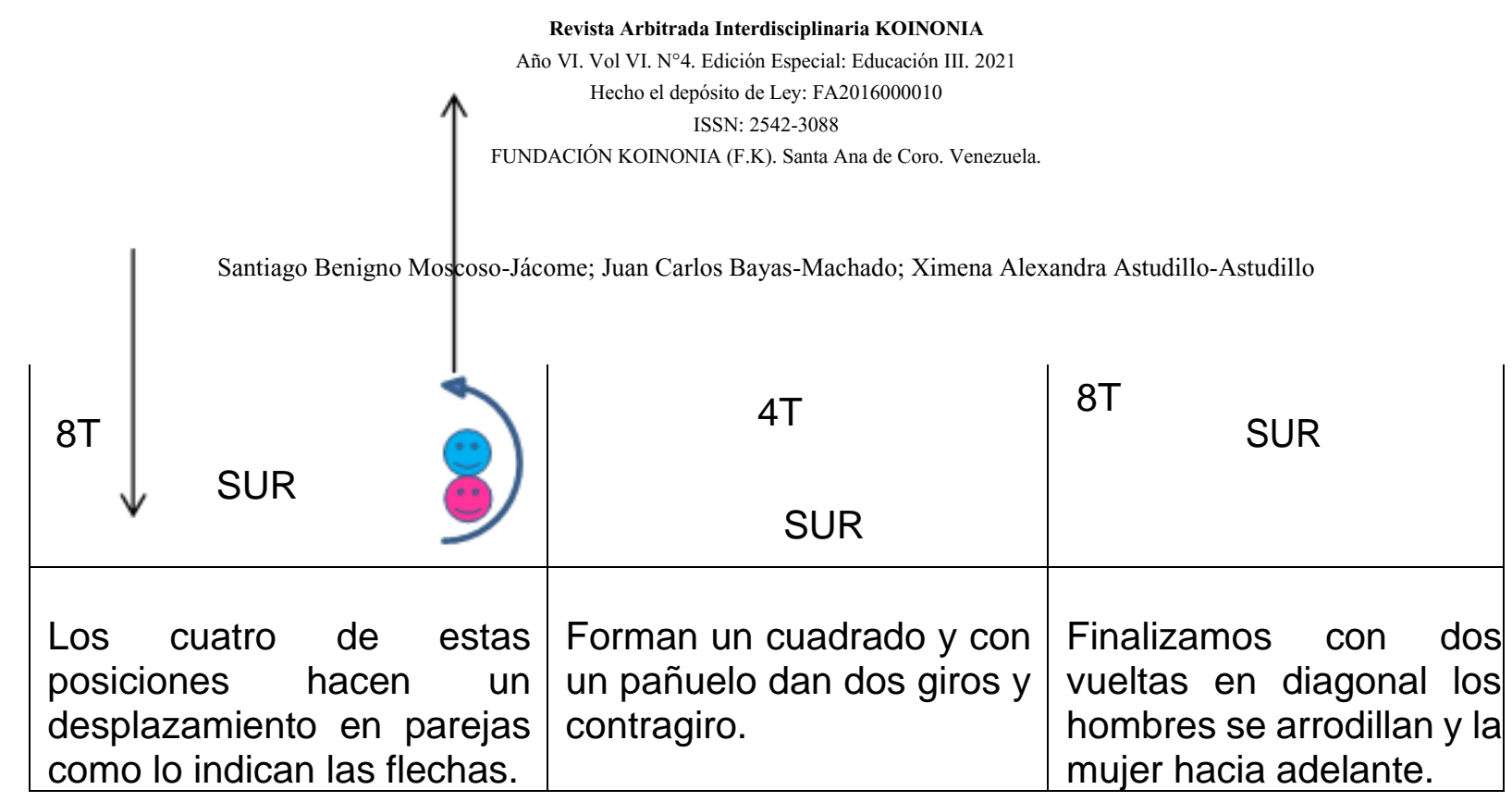

Gráfica 3. Coreografía del pasacalle

Fuente: Los autores

\section{CONCLUSIONES}

La guía metodológica desarrollada en esta investigación ayudará a los docentes a mejorar las clases aplicando nuevas estrategias para poder motivar en las actividades dictadas ayuda al desarrollo de la danza, aprender nuevas habilidades motrices básicas que permita una educación del cuerpo, movimiento y creatividad con estudiantes y docentes, creando educación interactiva e innovadora, que permita compartir otras culturas.

En los procesos de enseñanza aprendizaje el baile, ejercicios con música se hace lo más fácil y lúdico posible, es esencial que el docente utilice la guía metodología planteada en esta investigación.

Hay que recalcar que para trabajar coreografías, los profesionales de cualquier ámbito de la actividad física y el deporte deben conocer los elementos básicos del ritmo con una perspectiva metodológica. Los pasos de baile hacen viable que los docentes, puedan utilizar la danza en las clases de Educación Física y sirva como instrumento para el rescate cultural del país. 


\section{REFERENCIAS CONSULTADAS}

Ávila-García, Y., \& Veytia-Bucheli, M. (2019). Los procesos de enseñanza y aprendizaje de la danza: una mirada en atención a la diversidad estudiantil. Educación $Y$ Humanismo, 21(37), 67-85. https://doi.org/10.17081/eduhum.21.37.3410

Cadenillas, B. L. (2016). La danza como expresión artística y las habilidades motrices básicas en estudiantes de 5 años de edad de la Institución Cuna-Jardín "Mesa Redonda" San Martín de Porres, 2016. https://repositorio.ucv.edu.pe/handle/20.500.12692/28199

De la Torre, H., \& Coba, J. (2013). La expresión de los lenguajes no verbales en la danza de la comunidad indígena "La Calera" de la ciudad de Cotacachi en las fiestas de San Juan. Repositorio digital Universidad Central del Ecuador, 18-51.

DINADER. (1981). los Programas de estudio de Educación Física, Deportes y Recreación. Quito.

Erazo Álvarez, J. C. (2021). Capital intelectual y gestión de innovación: Pequeñas y medianas empresas de cuero y calzado en Tungurahua-Ecuador. Revista De Ciencias Sociales, 27, 230-245. Recuperado a partir de https://www.produccioncientificaluz.org/index.php/rcs/article/view/37004

Erazo, J. y Narváez, C. Medición y gestión del capital intelectual en la industria del cuero - calzado en Ecuador. Revista Arbitrada Interdisciplinaria Koinonía, 5 (9), 437-467. Recuperado a partir de https://n9.cl/ae0hc

Ferreira, M. (2009). Un enfoque pedagógico de la danza. Recuperado de https://n9.cl/wx5ar

Lozano, C. (2012). Todo esto plantea la necesidad de expresar nuestros sentimientos desde una perspectiva creativa y artística desarrollando todas las potencialidades humanas que dan sentido y orientación al quehacer educativo. Universisad Pedagogica Nacional, Mexico.

Martin, M. (2005). Del movimiento a la danza en la educación musical. Murcia: /revistas.um.es. 
Escobar, M. (2005). Del movimiento a la danza en la educación musical. Educatio siglo XXI: Revista de la Facultad de Educación, ISSN 1699-2105, №. 23, 2005 (Ejemplar dedicado a: Convergencia europea), pags. 125-140. 23. https://n9.cl/8j5n1

Mineduc. (2012). Curriculo de Educación Física. Mineduc, Quito.

Mineduc. (2014). Consolidado final . Riobamba.

Mineduc. (2016). Curriculo de Educación Física. Mineduc, Quito. Obtenido de https://n9.cl/x1v3

Monroy, M. (2003). Una pregunta por la pedagogía de la danza en la escuela. Redalyc Educación y Educadores, 159-167.

Montufar, K. (2011). La danza folclórica ecuatoriana : examen y prospectivas para promover su implementación en el currículum de niños en edad pre escolar. Guayaquil: Pontificia Universidad Catolica. 